\title{
Post-breeding at-sea movements of three central-place foragers in relation to submesoscale fronts in the Southern Ocean around Bouvetøya
}

\author{
ANDREW D. LOWTHER ${ }^{1}$, CHRISTIAN LYDERSEN ${ }^{1}$, MARTIN BIUW ${ }^{1,2}$, P.J. NICO DE BRUYN ${ }^{3}$, \\ GREG J.G. HOFMEYR ${ }^{4}$ and KIT M. KOVACS ${ }^{1}$ \\ ${ }^{1}$ Norwegian Polar Institute, Fram Centre, N-9296 Tromsø, Norway \\ ${ }^{2}$ Aquaplan-niva, Fram Centre, N-9296 Tromsø, Norway \\ ${ }^{3}$ Mammal Research Institute, Department of Zoology and Entomology, University of Pretoria, Private Bag X20, Hatfield 0028, \\ Pretoria, South Africa \\ ${ }^{4}$ Port Elizabeth Museum at Bayworld, Humewood 6013, Port Elizabeth, South Africa \\ andrew.lowther@npolar.no
}

\begin{abstract}
At-sea behaviour of central-place foraging fur seals and penguins in the Southern Ocean is understudied during the latter stages of parental care and the subsequent pre-moulting period. This biologically important period is costly to investigate due to the risk (or certainty) of losing tracking instruments when the animals moult. Early in this period, parents must meet the increasing demands of larger, more mobile offspring that are still nutritionally dependent and then the parents must recover lost body condition prior to the onset of their annual moult. This study reports late-season, at-sea movement patterns of macaroni penguins, chinstrap penguins and adult female Antarctic fur seals from the subantarctic island Bouvetøya, in relation to remotely-sensed oceanographic features. Foraging trips differing significantly in direction and distance travelled compared to those performed earlier in the breeding season, coincide with the time when offspring would be expected to become independent. On these trips, macaroni penguins moved towards the Polar Front while chinstrap penguins and Antarctic fur seals moved southward. Individuals from all three species appeared to target submesoscale ocean features once they were presumed to have been released from the constraints of feeding their young and were able to travel greater distances from the colony.
\end{abstract}

Received 20 August 2013, accepted 7 March 2014, first published online 29 May 2014

Key words: foraging ecology, fur seals, hidden Markov models, oceanography, penguins, telemetry

\section{Introduction}

Bouvetøya is a subantarctic island in the Atlantic sector of the Southern Ocean. It is the only island in a vast ocean sector, c. $2200 \mathrm{~km}$ from the south-west coast of South Africa. The island hosts the second largest breeding colony of Antarctic fur seals (Arctocephalus gazelle (Peters)) with over 15000 pups born annually (Hofmeyr et al. 2005). The site of the seal colony, on the coastal platform of Nyrøysa, is also home to a mixed breeding colony of penguins, with a small group of macaroni penguins (Eudyptes chrysolophus Brandt) (c. 1100 breeding pairs) and a very small group of chinstrap penguins (Pygoscelis antarctica Forster) $(<40$ breeding pairs) occupying the sloped edges at the northern periphery of the seal breeding beach. The few studies that have investigated the at-sea behaviour of the marine predators at Bouvetøya have focussed on intraand inter-specific differences in diving and at-sea movement behaviour during the breeding period (Biuw et al. 2009, Blanchet et al. 2013). During this time, fur seal mothers and penguin parents are constrained to a strict central-place foraging strategy because of the need to return at short intervals to feed their young. Spatial predictability and proximity of resources is probably more important than the richness of prey availability per se during this time.

Outside the breeding period, central-place foragers, such as fur seals and penguins, are known to travel more broadly (e.g. Boyd et al. 1998). This release might allow them to target prey resources at oceanographic hot spots that are not accessible to them during the breeding period. In the marine environment, eddies, fronts, convergence zones and filaments, which are the manifestation of water movement in response to bathymetry, wind, temperature and salinity, are typically associated with elevated levels of primary productivity at both mesoscale $(>100 \mathrm{~km})$ and submesoscale $(>10 \mathrm{~km})$ (Strass et al. 2002, Nordstrom et al. 2013). Additionally, weakly-swimming and buoyant organisms, such as plankton, are advected into such areas by strong currents (Olson \& Backus 1985). Although their spatially and temporally transient nature might limit their usefulness during the breeding season, these productive patches of ocean probably attract higher trophic marine 
predators during periods when they can travel far enough to exploit them ( $\mathrm{Nel}$ et al. 2001).

In the Atlantic sector of the Southern Ocean, the physical oceanography in terms of the location and structure of water masses is now reasonably wellcharacterized. From north to south, the four major fronts delineating water masses are the Subantarctic Front (SAF, c. $\left.50^{\circ} \mathrm{S}\right)$, the Polar Front $\left(\mathrm{PF}, c .54^{\circ} \mathrm{S}\right)$, the Southern Antarctic Circumpolar Current Front (SACCF, c. $60^{\circ} \mathrm{S}$ ) and the Southern Boundary (SB, c. $70^{\circ} \mathrm{S}$ ) (Pakhomov \& McQuaid 1996, Abbott et al. 2000). South of the PF, waters are high in nutrients but low in chlorophyll $a$, with spring phytoplankton blooms restricted by light levels and mixing in the water column (Abbott et al. 2000). Within this broad region, accumulation of phytoplankton occurs along frontal areas, and the concomitant high densities of Antarctic krill (Euphausia superba Dana) that feed on the phytoplankton underpin a food chain that supports large populations of higher trophic predators (Reid \& Croxall 2001). Dense concentrations of myctophid fish are also typically found within frontal systems (Pakhomov et al. 1996). Summer post-larval krill swarms tend to form over shelves and at shelf-breaks where planktonic food resource densities are greatest, around the Antarctic continent and around isolated subantarctic islands, and then shift southwards towards the SACCF at the beginning of autumn (Atkinson et al. 2008). This southern shift is matched by the onset of nutritional independence of offspring in many subantarctic centrally-foraging species, such as Antarctic fur seals (Doidge \& Croxall 1989), macaroni penguins (Williams \& Croxall 1991) and chinstrap penguins (Trivelpiece et al. 1987). However, Bouvetøya's shelf extends only $c .25 \mathrm{~km}$ before reaching the western $1000 \mathrm{~m}$ isobath (Blanchet et al. 2013), after which the bathymetry drops to great depths very rapidly. Thus, it is probable that top predators in this region must depend more heavily on prey-aggregating transient ocean features to find prey compared to conspecifics elsewhere. These features may be more important late in the season when near shore prey densities are greatly reduced compared to islands due to predation pressure. This makes studying the late- and post-breeding period(s) of Bouvetøya's predators particularly interesting.

Characterizing at-sea behaviour of otariids and penguins during late-breeding and early post-breeding phases is problematic due to high rates of tag loss. Tags used to collect location data at-sea are traditionally attached to the fur or feathers using glue or tape and hence will be lost when animals moult (during the latter stages of the parental care phase or into the early postbreeding period). Consequently, only a few studies of movement behaviour have taken place during these latter stages (Boyd et al. 1998, 2002). However, this understudied period represents a time during which a reduction in the constraints to adult feeding occurs
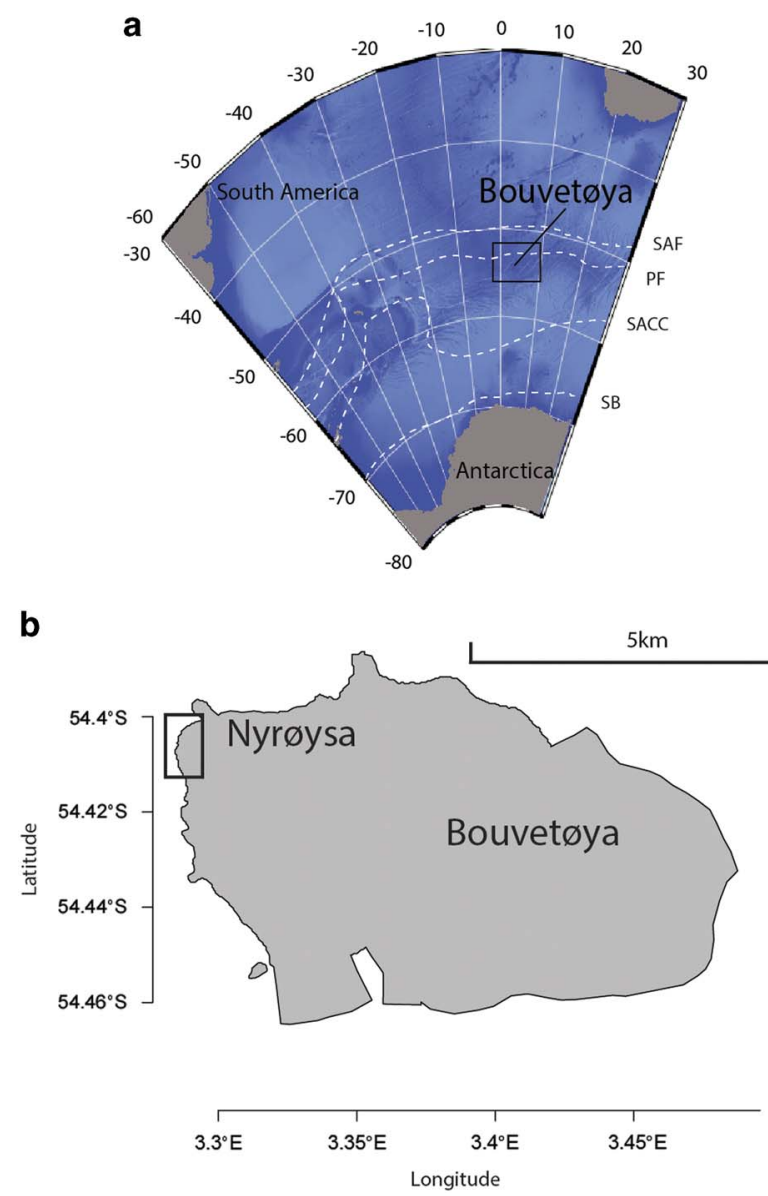

Fig. 1. a. Location of Bouvetøya in the Southern Ocean in relation to the Subantarctic Front (SAF), Polar Front (PF), Southern Antarctic Circumpolar Current (SACC) and the Southern Boundary (SB). b. Map of Bouvetøya showing the location of the study site at Nyrøysa.

(Staniland et al. 2012), and it also represents a critical window for the recovery of body condition between weaning/fledging and the onset of energetically costly moult of fur or feathers (Croxall 1982). Consequently, this study had two inter-dependent aims: i) to characterize how adult individuals from each species alter their movement behaviour during the transition from parental care into the early post-breeding period, and ii) to explore at-sea movements of three top trophic marine predators during their longer late-breeding foraging trips in relation to mesoscale and submesoscale oceanographic structures.

\section{Materials and methods}

\section{Study site and sampling}

This study was conducted at Nyrøysa on the west coast of Bouvetøya in the Southern Ocean $\left(54^{\circ} 23^{\prime} \mathrm{S} 3^{\circ} 47^{\prime} \mathrm{E}\right.$; Fig. 1) 
Table I. Mean maximum distance travelled and tracking duration for macaroni and chinstrap penguins, and trip duration and mean distance travelled for Antarctic fur seals at Bouvetøya.

\begin{tabular}{|c|c|c|c|c|c|}
\hline \multirow[t]{2}{*}{ ID } & \multirow[t]{2}{*}{ Instrumentation date } & \multirow[t]{2}{*}{ Tracking duration (days) } & \multirow[t]{2}{*}{ Trips $(n)$} & \multicolumn{2}{|c|}{ Mean maximum distance from colony $(\mathrm{km} \pm \mathrm{SD}(n))$} \\
\hline & & & & Pre & Post \\
\hline \multicolumn{6}{|l|}{ Macaroni penguins } \\
\hline \#L & $25 / 01 / 2008$ & 50.1 & 11 & $107.4 \pm 94.4(10)$ & $365.9(1)$ \\
\hline$\# \mathrm{O}$ & $29 / 01 / 2008$ & 30.5 & 15 & $53.4 \pm 34.6(15)$ & - \\
\hline \#U & $06 / 02 / 2008$ & 33.6 & 8 & $37.9 \pm 32.9(7)$ & $394.2(1)$ \\
\hline \#V & $05 / 02 / 2008$ & 44.5 & 10 & $62.9 \pm 29.9(9)$ & $572.2(1)$ \\
\hline \#26 & $30 / 01 / 2008$ & 24.1 & 1 & $13.4(1)$ & - \\
\hline \#29 & 01/02/2008 & 28.8 & 7 & $38.2 \pm 30.2(6)$ & $152.4(1)$ \\
\hline \#30 & $02 / 02 / 2008$ & 44.0 & 5 & $24.2 \pm 16.5(5)$ & - \\
\hline \#31 & $02 / 02 / 2008$ & 34.8 & 2 & $12.4(1)$ & $270.2(1)$ \\
\hline \multirow{2}{*}{\multicolumn{4}{|c|}{ Antarctic fur seals }} & \multicolumn{2}{|c|}{ Mean trip $( \pm \mathrm{SD})$} \\
\hline & & & & Duration (days) & Distance (km) \\
\hline \#B899 & $24 / 01 / 2008$ & 31.5 & 7 & $2.6 \pm 2.1$ & $83.2 \pm 53.1$ \\
\hline
\end{tabular}

'Pre' and 'Post' refer to mean maximum distance of foraging trips conducted prior to and after the first long excursion (assumed to mark chick fledging).

as part of the 2007-08 Norwegian Antarctic Research Expedition (NARE). It involved the collection of geospatial data from lactating Antarctic fur seals, breeding chinstrap penguins of both sexes and female macaroni penguins. All three species breed during the summer, with Antarctic fur seals having the longest breeding period (mid-November until late March), whereas both penguin species commence breeding later (late December) and fledge their offspring earlier (early March) (Blanchet et al. 2013). For this study, non-dutycycled platform terminal transmitters (PTTs) were deployed on Antarctic fur seals (Kiwisat 101, Sirtrack Ltd; $156 \times 62 \times 19 \mathrm{~mm}, 275 \mathrm{~g}$ ) and both penguin species (Kiwisat 202, Sirtrack Ltd; 136 x 44 x 59 mm, $260 \mathrm{~g}$ ). For detailed descriptions of capture, handling and instrumentation see Blanchet et al. (2013). Data from the parental care period until mid-February are published in Blanchet et al. (2013). Data from one of the seven chinstrap penguins that undertook a long directed post-breeding trip to the South Sandwich Islands are published in Biuw et al. (2010). Herein, the movements recorded via PTTs attached to seven animals of each of the three study species are explored. At the start of this late-breeding season study period all individuals were still caring for offspring.

\section{Location data processing}

ARGOS-derived locations are classified into location classes (LC), which have associated errors of varying magnitude, ranging from $<250 \mathrm{~m}(\mathrm{LC}-3)$ to $>100 \mathrm{~km}$ (LC-B) (Vincent et al. 2002). In this study, raw ARGOS data were pre-processed to remove extreme outliers by removing locations with unclassified error estimates (LC-Z). Further filtering involved estimating locations using a Kalman filter under a continuous-time state-space framework using the 'crawl' package (Johnson et al. 2008 ) in program $R$ ( $R$ core team 2013). New locations were interpolated along each animal's filtered track to reduce sampling bias incurred via the temporally irregular transmission of location data. Trips close to the colony resulted in too few at-sea locations being transmitted to be able to differentiate discrete excursions. Furthermore, the modelled accuracy of positions is such that estimated locations within $5 \mathrm{~km}$ of the colony may still represent the animal residing on land (Patterson et al. 2010). Thus, only trips in which the animals travelled $\geq 5 \mathrm{~km}$ from the colony are considered in our analyses (Boersma et al. 2009).

\section{At-sea behavioural estimation under a state-space framework}

Hidden Markov models (HMMs) were used to make inferences on the behavioural state of animals along their tracks. Estimated locations were considered accurate enough to allow for direct calculation of movement metrics (turning angle and speed) which were subsequently used as inputs into the HMMs. Behaviour was classified into one of two states, either 'resident' or 'transient', based on estimated speeds and turning angles between successive locations along each filtered track (Patterson et al. 2009). Distributions of turning angles and speed estimates were modelled using Weibull and wrapped Cauchey distributions, respectively (Jonsen et al. 2012). 


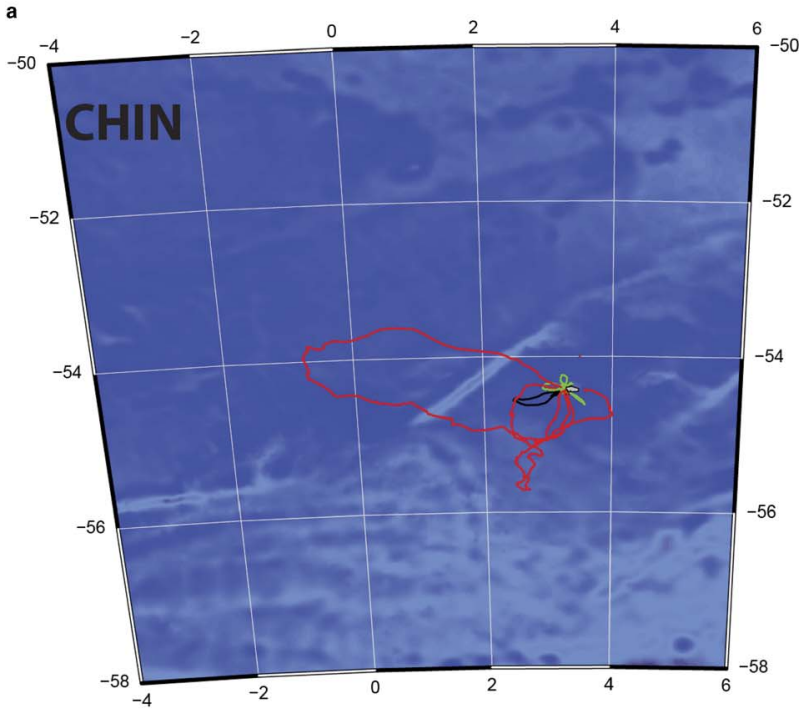

b
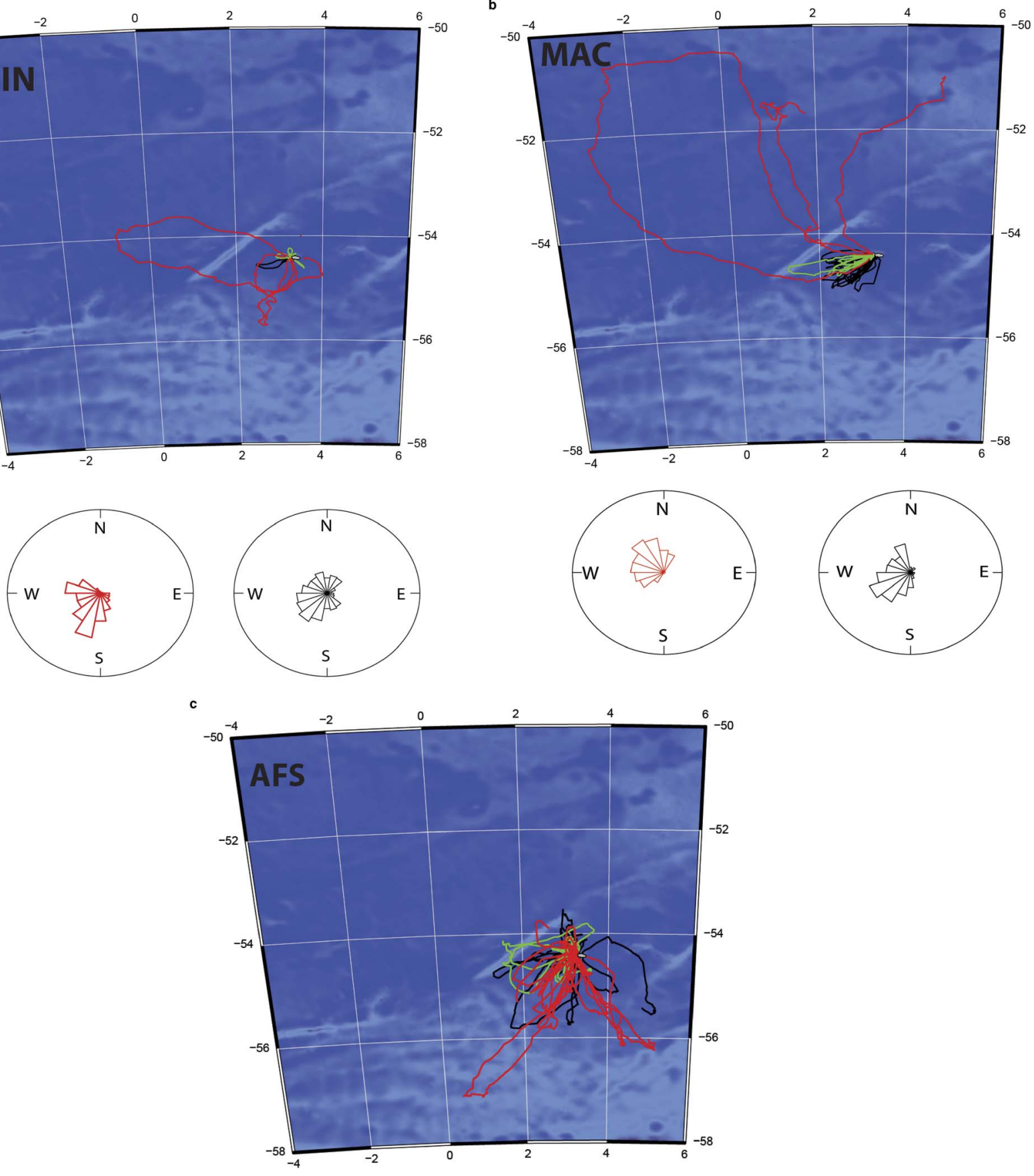

Fig. 2. Filtered, interpolated tracks from a. chinstrap penguins $(\mathrm{CHIN}, n=5)$, b. macaroni penguins $(\mathrm{MAC}, n=5)$, and c. Antarctic fur seals (AFS, $n=5$ ) during the summer 2008. Green tracks were performed from the time of tagging until 15 February (early-mid-breeding, Blanchet et al. 2013). Black tracks denote trips made late in the breeding season (16 February until the first extended trip) and red tracks represent late- or post-breeding tracks. Compass roses show the mean direction of travel for macaroni and chinstrap penguins colour-coded to match the tracks from the various breeding-season stages.

\section{Statistical analysis}

Foraging trip duration (days), total distance travelled and maximum distance from the colony (great circle method, $\mathrm{km}$ ) were calculated at the level of individual foraging trips. For at-sea events of both penguin species that were not captured in discrete foraging trips, the straight-line maximum distance of locations from the colony were calculated. To determine whether animals changed the direction in which they travelled to foraging 
Table II. General logistic regression model coefficient estimates and parameters for optimum models used to explore the effect of mean sea level anomaly (MSLA), sea surface temperature (SST) and respective gradients, as well as submesoscale fronts described by finite-scale Lyapunov exponents (FSLE) and the interactions between each parameter for macaroni penguins, chinstrap penguins and Antarctic fur seals. The optimum model for each individual was selected using Akaike information criteria corrected for small sample size (AICc; see Supplemental Table I for model selection tables for each individual found at http://dx.doi.org/10.1017/S0954102014000170). Variance inflation factor (VIF) values $<10$ were considered to satisfy the requirements of minimal multicolinearity between predictor variables. In cases of multiple foraging trips for a single individual, the total variance in the model described by the random effect of foraging trip is reported (1/trip). In all cases, higher FSLE generally resulted in a greater probability of individuals adopting resident behaviour. The probability of individuals being resident increased in areas characterized by higher MSLA gradients and lower absolute MSLA values for all three species.

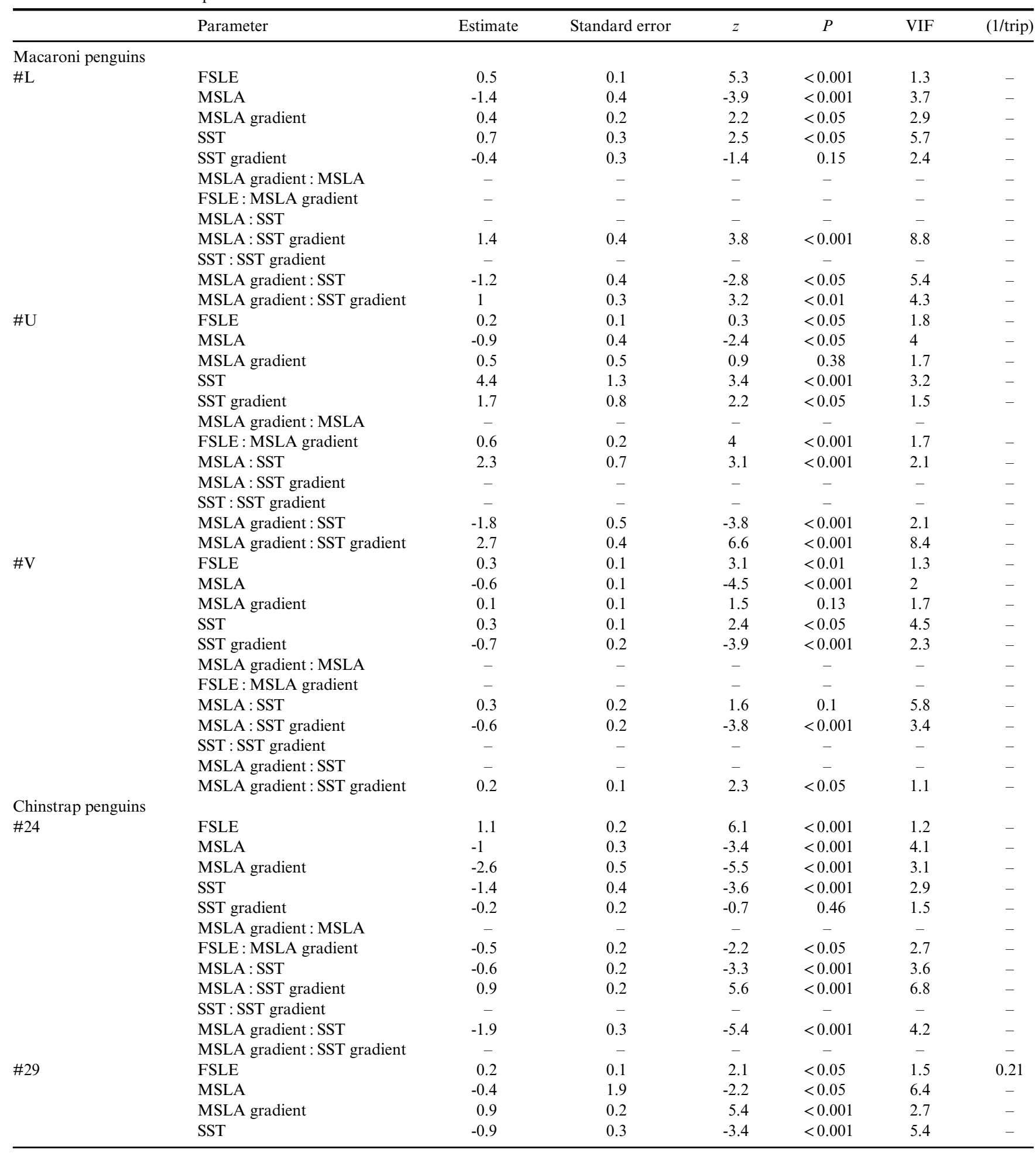


Table II. Continued

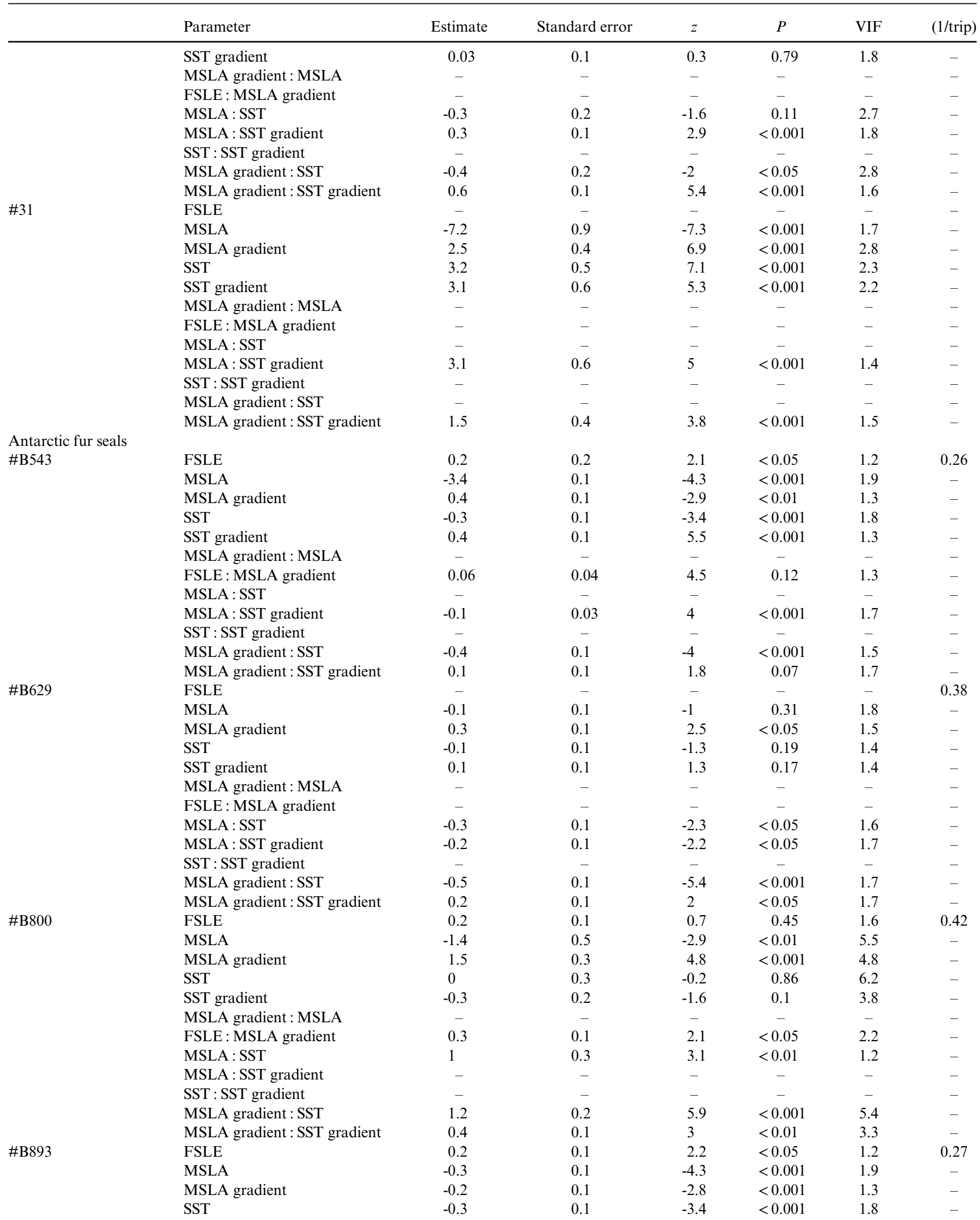


Table II. Continued

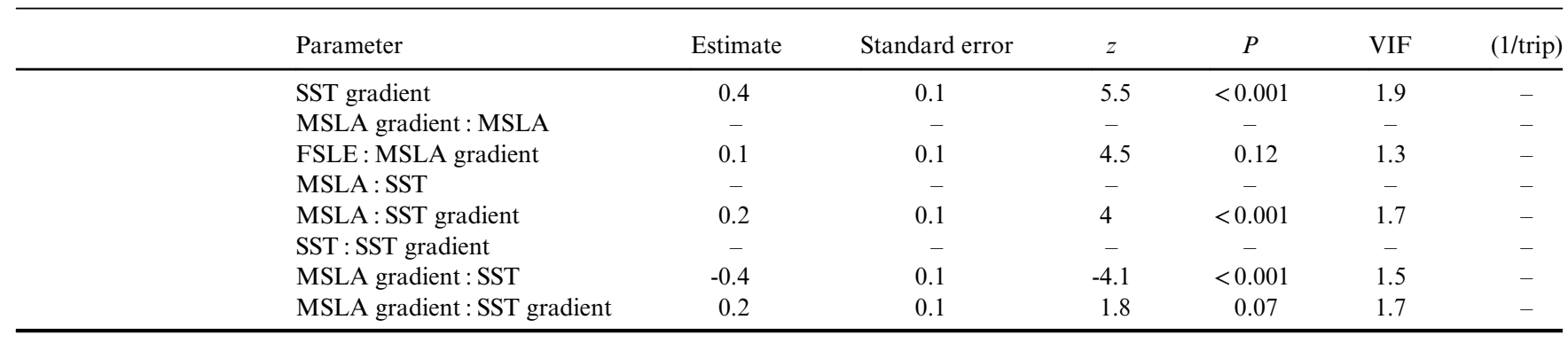

grounds throughout the study, the bearing between the colony and each interpolated location within each foraging trip was calculated and differences in the mean bearing of at-sea locations relative to the breeding colony were tested using circular ANOVA (cANOVA). All circular statistical analyses were conducted using the $\mathrm{R}$ packages 'circular' and 'CircStat'.

The mesoscale environment around Bouvetøya during the study period was characterized using satellite-derived maps of AVISO mean sea level anomaly (MSLA; $0.25^{\circ}$ and $7 \mathrm{~d}$ resolution) and AquaMODIS sea surface temperature (SST; $0.05^{\circ}$ and $8 \mathrm{~d}$ resolution). Positive gradient values of MSLAs represent mesoscale convergence zones, which are often associated with nutrient upwelling and the concentration of primary productivity (Hyrenbach et al. 2006). Each parameter was interpolated in Ocean Data View 4.5.3 using the DIVA algorithm (Schlitzer 2011) and the output rasterized in R (Hijmans et al. 2014). The Lagrangian finite-scale Lyapunov exponent (FSLE) technique was used to characterize submesoscale structures over 4-day periods to create maps of Lagrangian coherent structures (LCS) across the study area. The LCS are demarcation lines that separate dynamically different regions of fluid motion, a concept that has been recently employed to map filamentation, frontogenesis and transport barriers in oceanography (d'Ovidio et al. 2010) and their relationship to marine predator movements (Cotté et al. 2011). Maps of LCS can be defined in terms of FSLE, which measures the rate of separation of two tracer particles placed into a dynamic fluid from a known distance $\left(\delta_{0}\right)$ to a predetermined distance $\left(\delta_{\mathrm{f}}\right)$ over time $\tau$, following:

$$
\lambda=1 / \tau \log \delta_{\mathrm{f}} / \delta_{0} .
$$

The FSLE values are in units of $\mathrm{d}^{-1}$, reflecting the timescale of frontogenesis, and are calculated using geostrophic velocities derived from composite 4-day/ $0.25^{\circ}$ resolution maps of AVISO mean absolute dynamic topography. The FSLE is calculated via the integration of fluid movement over 200 days backwardsin-time, representing the evolution of converging structures that could influence the movement of animals (Cotté et al. 2011). Since FSLE incorporates information on the history of particle trajectories, it is possible to resolve fine-scale processes from coarse-scale remotely sensed data, typically to the scale over which particle separation was measured, which in this case was $0.04^{\circ}$ (Hernández-Carrasco et al. 2011). Additionally, following d'Ovidio et al. (2010), FSLE was only considered if it was greater than $0.1 \mathrm{~d}^{-1}$ because this value corresponds to the formation of submesoscale structures within monthly periods. Rasters of each environmental parameter were temporally matched with individual tracks and values were extracted at each interpolated location.

Generalized logistic models were used with a binomially distributed error function and a logit link to determine how environmental parameters influenced the likelihood of an individual displaying resident behaviour (Gilkinson et al. 2011). Given the different measurement units for each parameter, explanatory variables were standardized for each trip of each individual prior to analyses to facilitate interpretation of odds ratios. When multiple trips were recorded for an individual, logistic mixed effects models were used in order to enable the integration of random effects of individual foraging trips. Fixed effects and mixed effects logistic models were fitted by maximum likelihood using a Laplace approximation to the likelihood function and a penalized, iteratively reweighted least squares algorithm using the $\mathrm{R}$ Package 'Ime4' (Bates et al. 2012). All possible combinations of independent variables and their interactions were tested, with model selection (from all models with significant terms) based on Akaike information criteria corrected for small sample size (AICc). Estimates of the strength of multicolinearity were made by calculating the variance inflation factor (VIF) which provides an index of its severity. A maximum acceptable value of 10 was selected (Cherry et al. 2013), multicolinearity was deemed too severe (and models were rejected) at higher values.

All analyses were conducted using R 2.15.3 (R Core Team 2013) with results reported as mean \pm standard error unless otherwise stated. Results were considered to be statistically significant at $P<0.05$. 
a
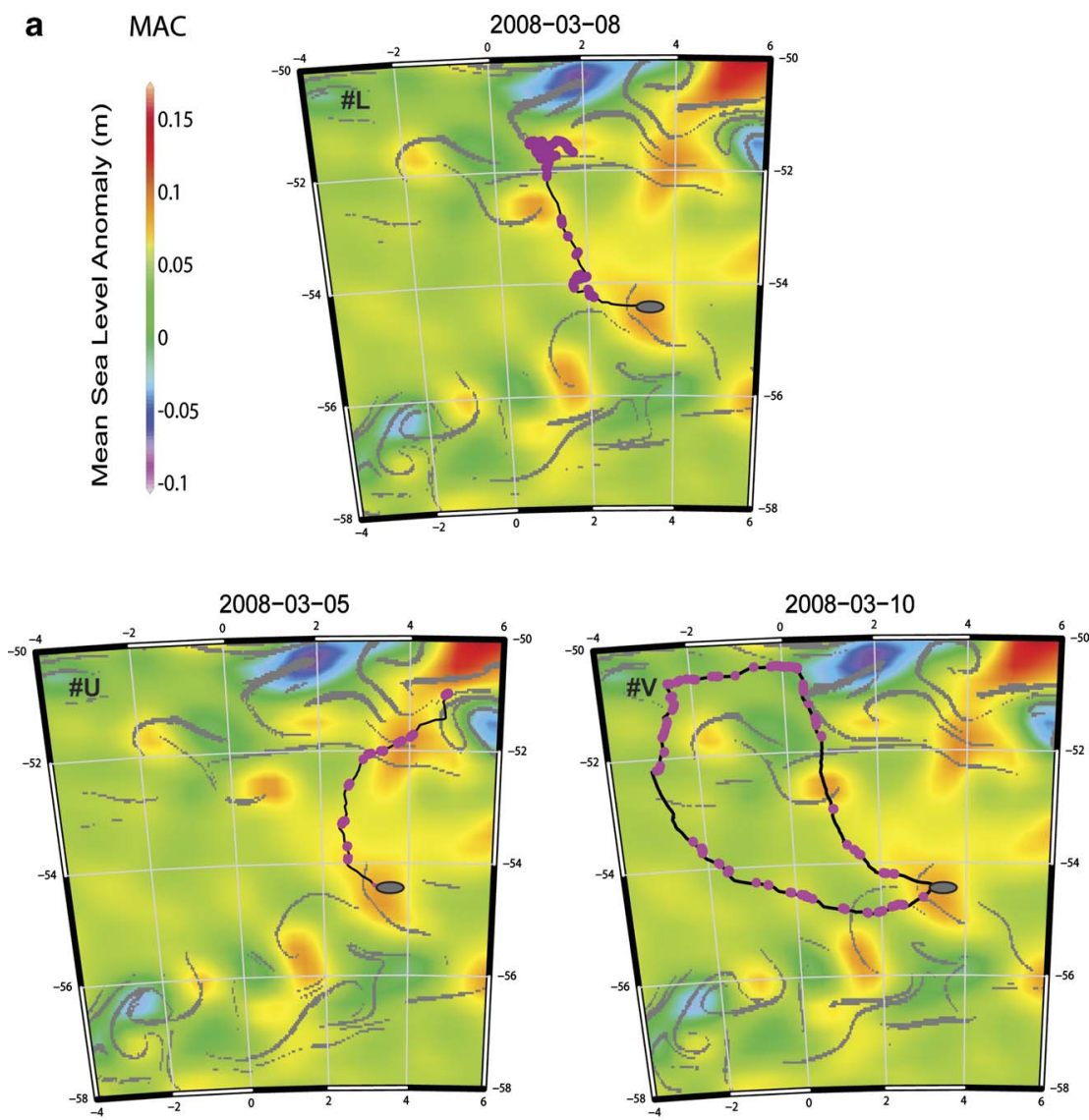

b
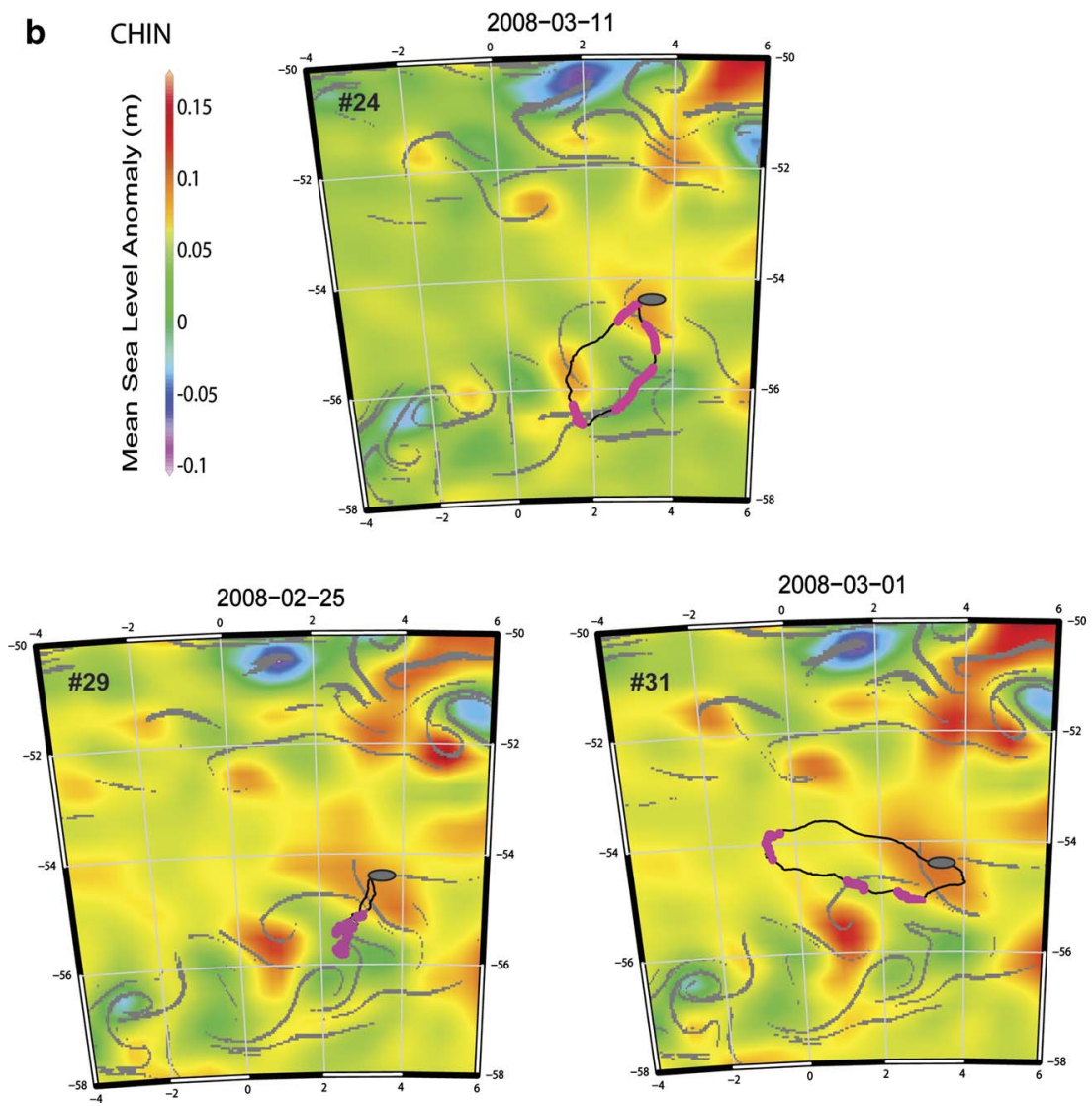

Fig. 3. For caption see next page 
c
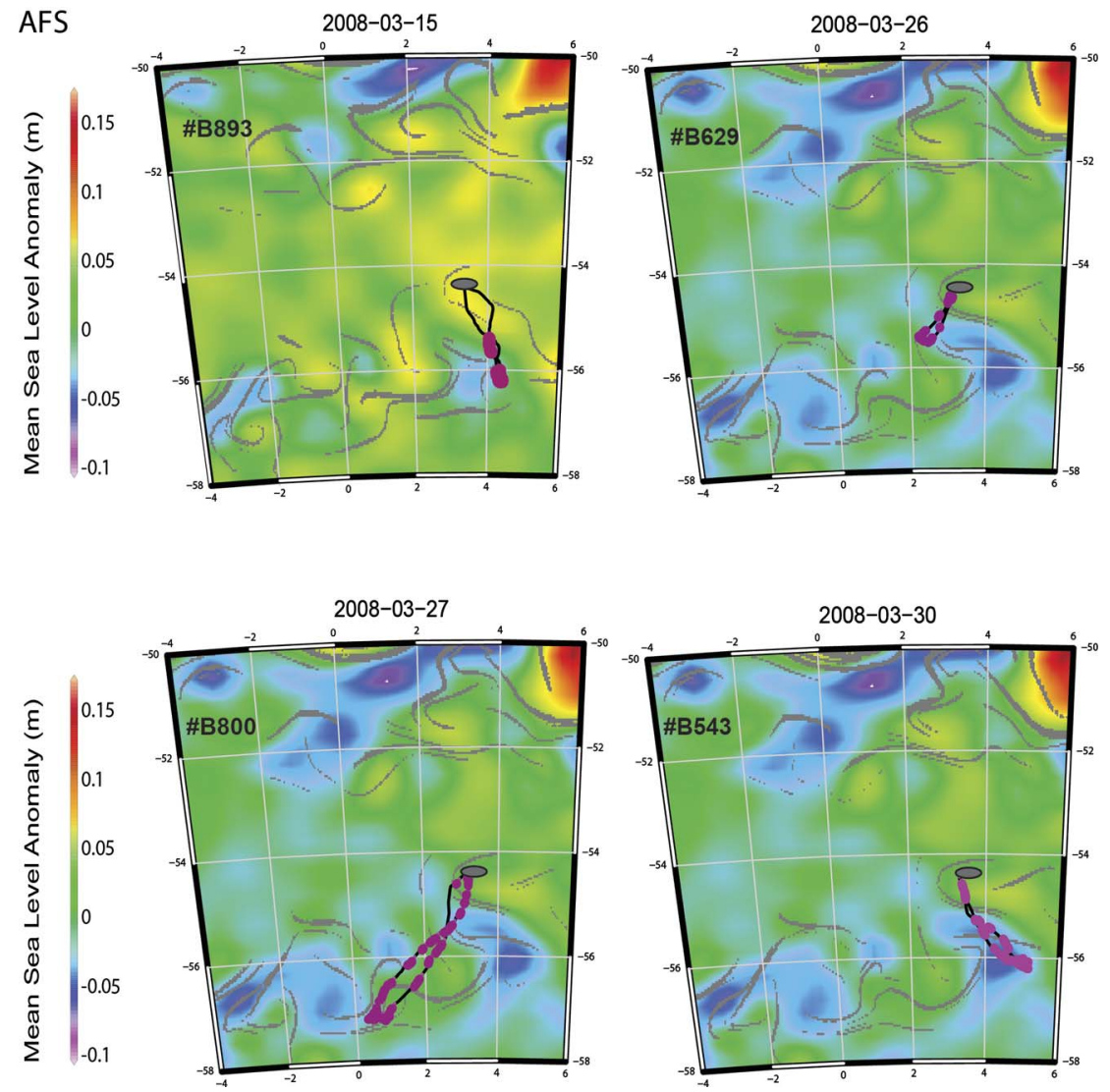

Fig. 3. Late-season foraging trips of a. macaroni penguins (MAC), b. chinstrap penguins (CHIN) and c. Antarctic fur seals (AFS) overlaid on temporallymatched mean sea level anomalies (MSLA). The location of Bouvetøya is represented by the grey ellipse (enlarged for visibility). Red points along the tracks depict areas of residency identified using hidden Markov models. Submesoscale fronts (Lagrangian coherent structures with finite-scale Lyapunov exponent (FSLE) $>0.1 \mathrm{~d}^{-1}$ ) are highlighted in grey. Individuals from all three predator species displayed greater residency probabilities in regions characterized by high MSLA gradients (colour gradients) and strong FSLE. Macaroni penguins tended to head north into areas with higher sea surface temperatures (SST), whereas Antarctic fur seals and chinstrap penguins travelled into areas with lower SST.

\section{Results}

Data from the PTTs on two macaroni penguins and one Antarctic fur seal was transmitted for only 10 days during the defined study period and were, therefore, not included in the analyses. Another Antarctic fur seal PTT provided only 52 location estimates over a three-month period thus these data were also removed from the final dataset. Similarly, one chinstrap penguin's PTT failed 22 days after deployment having only provided 15 location estimates and these data were likewise discarded. Consequently, the mean duration of geospatial datasets available for macaroni penguins $(n=5)$, chinstrap penguins $(n=5)$ and Antarctic fur seals $(n=5)$ were $38.2 \pm 8.6$ days (range 30.5-50.1 days), 35.9 \pm 9.9 days (range 24.1-47.8 days) and 68.3 \pm 23.7 days (range 31.5-93.2 days), respectively. The number of discrete trips identified and their associated metrics are summarized by species in Table I.

Visual inspection of FSLE maps showed a reasonably strong $\left(>0.15 \mathrm{~d}^{-1}\right)$ submesoscale filament located $c .40 \mathrm{~km}$ west of the Nyrøysa breeding colony on Bouvetøya, which persisted from January through until the end of March, along a prominent shelf-break that rises from $>3000 \mathrm{~m}$ to $c$. $500 \mathrm{~m}$ (Fig. S1 found at http://dx.doi.org/ 10.1017/S0954102014000170).
Individuals from both penguin species initially continued to forage in areas used early in the breeding period, immediately west and south of Bouvetøya (Fig. 2a $\&$ b; Blanchet et al. 2013), with mean maximum distances from the colony ranging between $12.4-38.2 \mathrm{~km}$ and $37.9-107.4 \mathrm{~km}$ for chinstrap and macaroni penguins, respectively (Table I). Location estimates from three penguins of each species that still had functioning transmitters at the beginning of March showed that individuals made at least one extended foraging trip prior to their transmitter(s) failing (Table I, Fig. 2). These late season trips differed significantly in terms of distance and mean bearing from the colony from trips conducted during the parental care period (mean maximum distance: Student's t-test $t=6.2, P<0.001$ in all cases; mean bearing: cANOVA $F=48.6, P<0.01$ in all cases; Fig. 2). During these trips both chinstrap and macaroni penguins had increased probabilities of adopting resident behaviour in regions characterized by stronger submesoscale filamentation (FSLE) (Table II). Macaroni penguins travelled a significantly greater distance from the colony during these longer trips than chinstrap penguins (Student's t-test $t=2.85$, df $=4, P<0.05$; Table I) and followed a more northerly bearing towards the PF (Fig. 2a \& b). The probability of macaroni penguins being in a resident behavioural state generally 
decreased in regions of positive MSLA. However, the probability increased in areas of stronger MSLA gradient and areas with positive SSTs (Table II, Fig. 3a). Irrespective of whether a macaroni penguin increased its residency time in regions of strong MSLA gradient or high SST, when encountering regions of strong MSLA gradient that were also characterized by high SST (represented by the model interaction term) the probably of the animal becoming resident increased (Table II). Conversely, the chinstrap penguins headed west and south but displayed a similar decrease in probability of resident behaviour in areas associated with increasing MSLA (Table II, Fig. 3b). The two chinstrap penguins that headed south-west (\#24 and \#29) showed decreased residency behaviour when confronted with lower SSTs, a pattern that was reversed in the bird that headed west (\#31) (Table II).

Antarctic fur seals displayed considerable variability in their direction of travel, both between individuals and between consecutive trips for the same individual (cANOVA $F>52.7, P<0.001$ in all cases; Fig. 2c and Fig. S2 found at http://dx.doi.org/10.1017/ S0954102014000170). They predominantly utilized at-sea habitat to the north-west and south-west of the colony, though individuals tracked until mid-April (\#B629 and \#B893) gradually performed more directed, southerly trips (Fig. S2). The probability of an individual Antarctic fur seal being in a resident state generally increased in the presence of increasing FSLE values and MSLA gradients (Table II, Fig. 3c). Conversely, the probability of an individual Antarctic fur seal displaying resident behaviour decreased in regions characterized by higher MSLA and SST values (Table II, Fig. 3c). In all cases, the random effect of trip explained at least $26 \%$ of the variability in the likelihood of an individual expressing residency behaviour (range $26-42 \%$, Table II).

\section{Discussion}

This study presents at-sea movement behaviour of three sympatrically-breeding, central-place foraging marine predators at a time when the constraints of offspring provisioning are ending. Using a multivariate approach, oceanographic parameters are incorporated into the analyses of the predators' at-sea movement patterns. It is only recently, with the advent of new telemetric devices, higher quality remote-sensed imagery and more advanced statistical tools, that these interactions can be quantified at submesoscales. Acknowledging the small sample sizes for the longer trips in late summer described in this study, it does appear that marked behavioural changes occurred toward (or upon) the termination of parental care and that residency behaviour became more focussed on finescale oceanographic features when individuals were free to travel further from the island.
During the parental care period, the limited fasting capabilities of offspring determines how long adults can be away from the colony and thus how far they can travel. Antarctic fur seals, macaroni penguins and chinstrap penguins are all pelagic foragers and as such they probably learn to track high density prey areas using oceanographic features, such as currents and temperature gradients. Given that the distribution of phytoplankton is typically more concentrated at eddy boundaries, filaments and fronts (d'Ovidio et al. 2010) it is reasonable to assume that mesopelagic fishes and other mid-trophic predators also aggregate at these dynamic features (Pakhomov \& McQuaid 1996). Indeed, the relative importance of transient oceanographic features was confirmed by a recent study of the at-sea distribution of these species at Bouvetøya even during the breeding season, with all three species foraging within $60 \mathrm{~km}$ of the colony in a region containing a filament that persisted throughout the period (Blanchet et al. 2013).

Several studies have previously shown a marked increase in distance travelled by marine predators upon the reduction or removal of constraints imposed by parental care (Drago et al. 2010). This study supports these findings; during late breeding and early postbreeding, individuals from all three species increased their residency time at convergence zones (regions of positive MSLA gradients) at both mesoscale and submesoscale levels. The willingness of individuals to travel great distances to track these zones suggests that this strategy is probably more profitable than remaining in the shelf waters surrounding Bouvetøya. The telemetry data from the penguins are particularly interesting given the general paucity of post-breeding/pre-moult movement information available for macaroni penguins and chinstrap penguins. Assuming that chick fledging did mark the commencement of longer foraging excursions for the birds, the data in this study are in broad agreement with the few similar telemetric studies available for this part of the annual cycle (Waluda et al. 2010).

The macaroni penguins in this study generally moved away from the southern regions that are associated with higher late-season krill densities towards the warmer waters at the northern boundary of the PF, a pattern that has been previously described (Barlow \& Croxall 2002). However, within these general trends, individual birds displayed notable variation in at-sea behaviour. For example, the probability of residency for macaroni penguin \#U was greatly enhanced in areas of strong SST gradient, a pattern not seen in the other two birds. Macaroni penguins are known to be generalist predators that consume both krill and myctophids (Green et al. 2005), the late-season movements suggest that the penguins preferentially targeted energy-dense myctophids in frontal zones associated with the PF as soon as they were freed of parental care (Pakhomov et al. 2000). The relationship 
between residency and oceanographic gradients is consistent with patterns seen in other marine predators, such as the northern fur seal Callorhinus ursinus L. (Nordstrom et al. 2013).

Data on chinstrap penguin diet during the breeding season suggests a heavy reliance on krill, with mesopelagic fish only appearing during periods of low krill abundance (Strass et al. 2002). However, little is known about their diet during longer pre-moult trips. In the present study, all the chinstrap penguins increased their residency in regions characterized by lower MSLA. Two of the birds headed on southerly bearings and became resident at submesoscale convergence zones in cooler waters, presumably targeting krill (Fig. 2). Interestingly, one bird (\#31) did not follow this pattern and instead moved westward into relatively warm waters. This individual's residency behaviour towards areas of high MSLA was positively modulated in the presence of stronger SST gradients, which may indicate an alternate foraging strategy relative to its tracked conspecifics. Given the short duration of tracking in the pre-moult period in this study, it is not possible to determine whether this behaviour persisted across multiple foraging trips or how prevalent this alternate behaviour is in the population. This individual may still have been targeting krill, as the increased survival costs incurred by krill in the warmer waters near the PF may be offset by more abundant food (Atkinson et al. 2008).

Mean foraging trip durations of adult female Antarctic fur seals in this study were consistent with those found for adult female Antarctic fur seals at South Georgia at a similar stage of lactation (Waluda et al. 2010). The slightly longer periods away from the colony in late lactation probably reflect increased fasting abilities of older pups. The data collection period probably does not extend into the post-lactation phase even in this extendedseason study. However, telemetry data from the Antarctic fur seals showed a similar pattern of movement to two of the chinstrap penguins, taking a progressively more southerly bearing of travel into cooler waters and generally increasing residency at convergence zones at both meso- and submesoscales.

\section{Conclusions}

Individual variability in the foraging behaviour of penguins and pinnipeds is becoming more frequently reported. Behavioural state estimation from telemetry data using techniques similar to those employed here are providing opportunities to model relationships between bottom-up drivers of food distribution and the at-sea movements of top marine predators. The occurrence of three species of central-place foraging predators at Bouvetøya, with different life history constraints, provides a fascinating opportunity to examine variability in foraging dynamics between individuals and species at multiple temporal scales in relation to oceanographic conditions. Incorporating information on diet, for example by the inclusion of biogeochemical tracers, should be the next step in quantifying the relationships between these predators and the environmental parameters that shape their foraging behaviour. Further investigation of the temporal and spatial predictability of fronts in the immediate vicinity of the island across years is also warranted, though the deployment of electronic tags capable of higher-resolution location estimation, such as GPS tags, would be needed in order to further elucidate the relative importance of these fronts to these predators. Additional tracking of both chinstrap and macaroni penguins during pre- and post-moult foraging trips should be conducted to test for interannual patterns and the consistency of utilization of oceanographic gradients by individuals that forage in different locations and potentially on different prey types.

\section{Acknowledgements}

This work was funded by the Norwegian Antarctic Research Expedition (NARE) programme awarded by the Norwegian Research Council. The authors thank Aline Arriola and Petrus Kritzinger for fieldwork help. Logistics support was provided by the Norwegian Polar Institute OLA Department and the South Africa National Antarctic Program (SANAP). We thank the captain and crew of the SA Agulhas for transport to and from the island, and Titan Helicopters Ltd for cargo and personnel transfer between the ship and the island. We also thank two anonymous reviewers who provided comments that were helpful in improving the manuscript.

\section{Supplemental material}

A supplemental table and two figures will be found at http://dx.doi.org/10.1017/S0954102014000170.

\section{References}

Авbott, M.R., Richman, J.G., Letelier, R.M. \& Bartlett, J.S. 2000. The spring bloom in the Antarctic Polar Frontal Zone as observed from a mesoscale array of bio-optical sensors. Deep-Sea Research Part II - Topical Studies in Oceanography, 47, 3285-3314.

Atrinson, A., Siegel, V., Pakhomov, E.A., Rothery, P., Loeb, V., Ross, R.M., Quetin, L.B., Schmidt, K., Fretwell, P. \& MurPhy, E.J. 2008. Oceanic circumpolar habitats of Antarctic krill. Marine Ecology Progress Series, 362, 1-23.

Barlow, K.E. \& Croxall, J.P. 2002. Seasonal and interannual variation in foraging range and habitat of macaroni penguins Eudyptes chrysolophus at South Georgia. Marine Ecology Progress Series, 232, 291-304.

Bates, D., Mächler, M. \& Bolker, B. 2012. Fitting linear mixed-effects models using lme4. Journal of Statistical Software, VV. 1-9. 
Biuw, M., Krafft, B.A., Hofmeyr, G.J.G., Lydersen, C. \& Kovacs, K.M. 2009. Time budgets and at-sea behaviour of lactating female fur seals Arctocephalus gazella at Bouvetøya. Marine Ecology Progress Series, 385, 271-284.

Biuw, M., Lydersen, C., de Bruyn, P.J.N., Arriola, A., Hofmeyr, G.G.J., Kritzinger, P. \& Kovacs, K.M. 2010. Long-range migration of a chinstrap penguin from Bouvetøya to Montagu Island, South Sandwich Islands. Antarctic Science, 22, 157-162.

Blanchet, M.A., Biuw, M., Hofmeyr, G.J.G., De Bruyn, P.J.N., Lydersen, C. \& Kovacs, K.M. 2013. At-sea behaviour of three krill predators breeding at Bouvetøya - Antarctic fur seals, macaroni penguins and chinstrap penguins. Marine Ecology Progress Series, 477, 285-302.

Boersma, P.D., Rebstock, G.A., Frere, E. \& Moore, S.E. 2009. Following the fish: penguins and productivity in the South Atlantic. Ecological Monographs, 79, 59-76.

Boyd, I.L., McCafferty, D.J., Reid, K., Taylor, R. \& Walker, T.R. 1998. Dispersal of male and female Antarctic fur seals (Actocephalus gazella). Canadian Journal of Fisheries and Aquatic Science, 55, 845-852.

Boyd, I.L., Staniland, I.J. \& Martin, A.R. 2002. Distribution of foraging by female Antarctic fur seals. Marine Ecology Progress Series, 242, 285-294.

Cherry, S.G., Derocher, A.E., Thiemann, G.W. \& Lunn, N.J. 2013. Migration phenology and seasonal fidelity of an Arctic marine predator in relation to sea ice dynamics. Journal of Animal Ecology, 82, 912-921.

Cotté, C., d'Ovidio, F., Chaigneau, A., Lévy, M., Taupier-Letage, I., Mate, B. \& Guinet, C. 2011. Scale-dependent interactions of Mediterranean whales with marine dynamics. Limnology and Oceanography, 56, 219-232.

CroXall, J.P. 1982. Energy costs of incubation and moult in petrels and penguins. Journal of Animal Ecology, 51, 177-194.

D’Ovidio, F., De Monte, S., Alvain, S., Dandonneau, Y. \& Lévy, M. 2010. Fluid dynamical niches of phytoplankton types. Proceedings of the National Academy of Sciences of the United States of America, 107, 18 366-18 370.

Doidge, D.W. \& Croxall, J.P. 1989. Factors affecting weaning weight in Antarctic fur seals Arctocephalus gazella at South Georgia. Polar Biology, 9, 155-160.

Drago, M., Cardona, L., Crespo, E.A., García, N., Ameghino, S. \& Aguilar, A. 2010. Change in the foraging strategy of female South American sea lions (Carnivora: Pinnipedia) after parturition. Scientia Marina, 74, 589-598.

Gilkinson, A.K., Finerty, S.E., Weltz, F., Dellapenna, T.M. \& DAvis, R.W. 2011. Habitat associations of sea otters (Enhydra lutris) in a soft- and mixed-sediment benthos in Alaska. Journal of Mammalogy, 92, 1278-1286.

Green, J.A., Boyd, I.L., Woakes, A.J., Warren, N.L. \& Butler, P.J. 2005. Behavioural flexibility during year-round foraging in macaroni penguins. Marine Ecology Progress Series, 296, 183-196.

Hernández-Carrasco, I., López, C., Hernández-García, E. \& Turiel, A. 2011. How reliable are finite-size Lyapunov exponents for the assessment of ocean dynamics? Ocean Modelling, 36, 208-218.

Hijmans, R.J., van Etten, J., Mattiuzzi, M., Sumner, M., Greenberg, J.A., Lamigueiro, O.P., Bevan, A., Racine, E.B. \& Shortridge, A. 2014. raster: geographic data analysis and modeling. http://cran. r-project.org/web/packages/raster.

Hofmeyr, G.J.G., Krafft, B.A., Kirkman, S.P., Bester, M.N., Lydersen, C. \& Kovacs, K.M. 2005. Population changes of Antarctic fur seals at Nyrøysa, Bouvetøya. Polar Biology, 28, 725-731.

Hyrenbach, K.D., Veit, R.R., Weimerskirch, H. \& Hunt, JR, G.L. 2006. Seabird associations with mesoscale eddies: the subtropical Indian Ocean. Marine Ecology Progress Series, 324, 271-279.

Johnson, D.S., London, J.M., Lea, M.A. \& Durban, J.W. 2008. Continuous-time correlated random walk model for animal telemetry data. Ecology, 89, 1208-1215.
Jonsen, I., Basson, M., Bestley, S., Bravington, M.V., Patterson, T.A., Pedersen, M.W., Thomson, R., Thygesen, U.H. \& Wotherspoon, S.J. 2012. State-space models for bio-loggers: a methodological road map. Deep-Sea Research Part II - Topical Studies in Oceanography, 88-89, 3446.

Nel, D.C., Lutjeharms, J.R.E., Pakhomov, E.A., Ansorge, I.J., Ryan, P.G. \& KLAGES, N.T.W. 2001. Exploitation of mesoscale oceanographic features by grey-headed albatross Thalassarche chrysostoma in the southern Indian Ocean. Marine Ecology Progress Series, 217, 15-26.

Nordstrom, C.A., Battaile, B.C., Cotté, C. \& Trites, A.W. 2013. Foraging habitats of lactating northern fur seals are structured by thermocline depths and submesoscale fronts in the eastern Bering Sea. Deep Sea Research Part II - Topical Studies in Oceanography, 88-89, 78-96.

OLSON, D.B. \& BACKUS, R.H. 1985. The concentrating of organisms at fronts: a cold-water fish and a warm-core Gulf Stream ring. Journal of Marine Research, 43, 113-137.

PАкномоv, E.A. \& McQuaid, C.D. 1996. Distribution of surface zooplankton and seabirds across the Southern Ocean. Polar Biology, 16, 271-286.

Pakhomov, E.A., Perissinotto, R. \& McQuaid, C.D. 1996. Prey composition and daily rations of myctophid fishes in the Southern Ocean. Marine Ecology Progress Series, 134, 1-14.

Pakhomov, E.A., Perissinotto, R., McQuaid, C.D. \& Froneman, P.W. 2000. Zooplankton structure and grazing in the Atlantic sector of the Southern Ocean in late austral summer 1993: Part 1. Ecological zonation. Deep-Sea Research Part I - Oceanographic Research Papers, 49, 1663-1686.

Patterson, T.A., Basson, M., Bravington, M.V. \& Gunn, J.S. 2009. Classifying movement behaviour in relation to environmental conditions using hidden Markov models. Journal of Animal Ecology, 78, 1113-1123.

Patterson, T.A., McConnell, B.J., Fedak, M.A., Bravington, M.V. \& HiNDELL, M.A. 2010. Using GPS data to evaluate the accuracy of state-space methods for correction of Argos satellite telemetry errors. Ecology, 91, 273-285.

R CORe Team. 2013. R: a language and environment for statistical computing. Vienna: R Foundation for Statistical Computing.

Reid, K. \& Croxall, J.P. 2001. Environmental response of upper trophic-level predators reveals a system change in an Antarctic marine ecosystem. Proceedings of the Royal Society - Biological Sciences, B268, 377-384.

Schlitzer, R. 2011. Ocean Data View 4.5.3 user's manual. Bremerhaven: Alfred Wegener Institute.

Staniland, I.J., Robinson, S.L., Silk, J.R.D., Warren, N. \& Trathan, P.N. 2012. Winter distribution and haul-out behaviour of female Antarctic fur seals from South Georgia. Marine Biology, 159, 291-301.

Strass, V.H., Garabato, A.C.N., Pollard, R.T., Fischer, H.I., Hense, I., Allen, J.T., Read, J.F., Leach, H. \& Smetacek, V. 2002. Mesoscale frontal dynamics: shaping the environment of primary production in the Antarctic Circumpolar Current. Deep-Sea Research Part II - Topical Studies in Oceanography, 49, 3735-3769.

Trivelpiece, W.Z., Trivelpiece, S.G. \& Volkman, N.J. 1987. Ecological segregation of Adélie, gentoo and chinstrap penguins at King George Island, Antarctica. Ecology, 68, 351-361.

Vincent, C., McConnell, B.J., Ridoux, V. \& Fedak, M.A. 2002. Assessment of Argos location accuracy from satellite tags deployed on captive gray seals. Marine Mammal Science, 18, 156-166.

Waluda, C.M., Collins, M.A., Black, A.D., Staniland, I.J. \& Trathan, P.N. 2010. Linking predator and prey behaviour: contrasts between Antarctic fur seals and macaroni penguins at South Georgia. Marine Biology, 157, 99-112.

Williams, T.D. \& Croxall, J.P. 1991. Annual variation in breeding biology of macaroni penguins, Eudyptes chrysolophus, at Bird Island, South Georgia. Journal of Zoology, 223, 189-202. 